\title{
Prehospital Ticagrelor in ST-Segment Elevation Myocardial Infarction
}

\author{
Gilles Montalescot, M.D., Ph.D., Arnoud W. van 't Hof, M.D., Ph.D., \\ Frédéric Lapostolle, M.D., Ph.D., Johanne Silvain, M.D., Ph.D., \\ Jens Flensted Lassen, M.D., Ph.D., Leonardo Bolognese, M.D., \\ Warren J. Cantor, M.D., Ángel Cequier, M.D., Ph.D., Mohamed Chettibi, M.D., Ph.D., \\ Shaun G. Goodman, M.D., Christopher J. Hammett, M.B., Ch.B., M.D., Kurt Huber, M.D., \\ Magnus Janzon, M.D., Ph.D., Béla Merkely, M.D., Ph.D., Robert F. Storey, M.D., D.M., \\ Uwe Zeymer, M.D., Olivier Stibbe, M.D., Patrick Ecollan, M.D., \\ Wim M.J.M. Heutz, M.D., Eva Swahn, M.D., Ph.D., Jean-Philippe Collet, M.D., Ph.D., \\ Frank F. Willems, M.D., Ph.D., Caroline Baradat, M.Sc., Muriel Licour, M.Sc., \\ Anne Tsatsaris, M.D., Eric Vicaut, M.D., Ph.D., and Christian W. Hamm, M.D., Ph.D., \\ for the ATLANTIC Investigators*
}

\section{ABSTRACT}

The authors' affiliations are listed in the Appendix. Address reprint requests to Dr. Montalescot at the Allies in Cardiovascular Trials Initiatives and Organized Networks (ACTION) Study Group, Institut de Cardiologie, Centre Hospitalier Universitaire Pitié-Salpêtrière, 47 Blvd. de l'Hôpital, 75013 Paris, France, or at gilles.montalescot@psl.aphp.fr.

*A complete list of the Administration of Ticagrelor in the Cath Lab or in the Ambulance for New ST Elevation Myocardial Infarction to Open the Coronary Artery (ATLANTIC) investigators is provided in the Supplementary Appendix, available at NEJM.org.

This article was published on September 1 , 2014, at NEJM.org.

N Engl J Med 2014;371:1016-27. DOI: 10.1056/NEJMoa1407024

Copyright (c) 2014 Massachusetts Medical Society.

\section{BACKGROUND}

The direct-acting platelet $\mathrm{P}_{2} \mathrm{Y}_{12}$ receptor antagonist ticagrelor can reduce the incidence of major adverse cardiovascular events when administered at hospital admission to patients with ST-segment elevation myocardial infarction (STEMI). Whether prehospital administration of ticagrelor can improve coronary reperfusion and the clinical outcome is unknown.

\section{METHODS}

We conducted an international, multicenter, randomized, double-blind study involving 1862 patients with ongoing STEMI of less than 6 hours' duration, comparing prehospital (in the ambulance) versus in-hospital (in the catheterization laboratory) treatment with ticagrelor. The coprimary end points were the proportion of patients who did not have a $70 \%$ or greater resolution of ST-segment elevation before percutaneous coronary intervention (PCI) and the proportion of patients who did not have Thrombolysis in Myocardial Infarction flow grade 3 in the infarct-related artery at initial angiography. Secondary end points included the rates of major adverse cardiovascular events and definite stent thrombosis at 30 days.

\section{RESULTS}

The median time from randomization to angiography was 48 minutes, and the median time difference between the two treatment strategies was 31 minutes. The two coprimary end points did not differ significantly between the prehospital and inhospital groups. The absence of ST-segment elevation resolution of $70 \%$ or greater after PCI (a secondary end point) was reported for $42.5 \%$ and $47.5 \%$ of the patients, respectively. The rates of major adverse cardiovascular events did not differ significantly between the two study groups. The rates of definite stent thrombosis were lower in the prehospital group than in the in-hospital group ( $0 \%$ vs. $0.8 \%$ in the first 24 hours; $0.2 \%$ vs. $1.2 \%$ at 30 days). Rates of major bleeding events were low and virtually identical in the two groups, regardless of the bleeding definition used.

\section{CONCLUSIONS}

Prehospital administration of ticagrelor in patients with acute STEMI appeared to be safe but did not improve pre-PCI coronary reperfusion. (Funded by AstraZeneca; ATLANTIC ClinicalTrials.gov number, NCT01347580.) 
FFECTIVE ANTIPLATELET THERAPY COMbining the inhibition of both thromboxane $\mathrm{A}_{2}$-dependent platelet aggregation and $\mathrm{P} 2 \mathrm{Y}_{12}$ receptors is necessary in patients undergoing percutaneous coronary intervention (PCI), particularly those with ST-segment elevation myocardial infarction (STEMI). Studies in this patient population have shown that the more intense $\mathrm{P}_{2} \mathrm{Y}_{12}$ receptor inhibition achieved with the use of prasugrel, ticagrelor, or cangrelor, as compared with clopidogrel, is associated with better clinical outcomes and a lower risk of stent thrombosis. ${ }^{1-5}$ The benefit was obtained with in-hospital administration of these drugs, and it is not known whether earlier administration would be as safe and possibly more effective.

The concept of prehospital administration of antiplatelet agents in primary PCI was first investigated with the glycoprotein IIb/IIIa inhibitor abciximab, which was associated with a higher rate of Thrombolysis in Myocardial Infarction (TIMI) flow grade 3 before primary PCI and lower rates of ischemic events, as compared with placebo. ${ }^{6}$ Further studies confirmed the benefit of earlier administration of glycoprotein IIb/IIIa inhibitors in patients with STEMI, especially in those presenting very soon after symptom onset. ${ }^{7-11}$ However, the benefit was less certain in patients at lower risk for ischemic events or presenting later. ${ }^{12,13}$

Various studies and meta-analyses suggested that pretreatment with clopidogrel in patients with STEMI could reduce the rate of ischemic events without excess bleeding, ${ }^{14-16}$ but its effectiveness may be limited by its slow onset of action and the variable response. In contrast, the new oral $\mathrm{P}_{2} \mathrm{Y}_{12}$-receptor antagonists inhibit platelet function in less than 1 hour, which is compatible with transfer times for primary PCI. ${ }^{17,18}$ Although some studies suggested that the full effect of prasugrel or ticagrelor on platelet function may take several hours in patients with STEMI, ${ }^{19-21}$ to our knowledge, these data have never been evaluated in relation to clinical outcomes.

Ticagrelor is a direct-acting inhibitor of the platelet $\mathrm{P}_{2} \mathrm{Y}_{12}$ receptor with a rapid antiplatelet effect. ${ }^{17,22}$ It has been shown to reduce the rate of major cardiovascular events among patients with acute coronary syndromes, as compared with clopidogrel, ${ }^{23}$ and has the potential to improve coronary reperfusion and the prognosis for patients with STEMI treated with primary PCI. ${ }^{24}$ The aim of the ATLANTIC (Administration of Ticagrelor in the Cath Lab or in the Ambulance for New ST
Elevation Myocardial Infarction to Open the Coronary Artery) study was to evaluate whether early, in-ambulance administration of ticagrelor could safely improve coronary reperfusion in patients with STEMI transferred for primary PCI.

\section{METHODS}

\section{STUDY DESIGN AND PATIENTS}

The ATLANTIC study was a phase 4, international, randomized, double-blind study. ${ }^{25}$ Patients were randomly assigned to receive either prehospital (in the ambulance) or in-hospital (in the catheterization laboratory) treatment with ticagrelor, in addition to aspirin and standard care. The clinical study protocol is available with the full text of this article at NEJM.org. The coordinating center was the Allies in Cardiovascular Trials Initiatives and Organized Networks (ACTION) Study Group at Pitié-Salpêtrière Hospital. The trial design and protocol were approved by the national regulatory authorities in all the participating countries and by the local ethics committee or institutional review board at each participating site. All the patients provided written informed consent.

Eligible patients, identified by ambulance personnel after STEMI had been diagnosed, had a symptom duration of more than 30 minutes but less than 6 hours, with an expected time from the qualifying electrocardiogram (ECG) to the first balloon inflation of less than 120 minutes. Randomization and the first loading dose of the study drug took place immediately after the diagnostic ECG and before the administration of a loading dose of any $\mathrm{P}_{2} \mathrm{Y}_{12}$-receptor antagonist. Patients were then transferred to a hospital to undergo coronary angiography, with or without PCI.

\section{STUDY PROCEDURES}

In the prehospital group, patients received a 180-mg loading dose of ticagrelor before transfer and then a matching placebo in the catheterization laboratory. Patients in the in-hospital group received a placebo before transfer and then a $180-\mathrm{mg}$ loading dose of ticagrelor in the catheterization laboratory. All the patients subsequently received ticagrelor at a dose of $90 \mathrm{mg}$ twice daily for 30 days, with a recommendation that treatment be continued for a total of 12 months. In-ambulance use of glycoprotein IIb/IIIa inhibitors was discouraged but was left to the physician's discretion. In-laboratory use of glycoprotein IIb/IIIa inhibitors after angiography had to be identified as either 
a strategy of choice or a bailout treatment during PCI. A pharmacodynamic substudy was conducted at five participating centers, the main end point of which was the result of a phosphorylation assay for measuring the platelet-reactivity index of a vasodilator-stimulated phosphoprotein at the start of catheterization (before PCI). ${ }^{25}$

\section{STUDY END POINTS}

The coprimary end points were the proportion of patients who did not have $70 \%$ or greater resolution of ST-segment elevation before PCI and the proportion of patients who did not meet the criteria for TIMI flow grade 3 in the infarct-related artery at angiography before PCI. Prespecified secondary end points included the composite of death, myocardial infarction, stent thrombosis, stroke, or urgent revascularization at 30 days; definite stent thrombosis at 30 days; thrombotic bailout with glycoprotein IIb/IIIa inhibitors; TIMI flow grade 3 at the end of the procedure; and complete $(\geq 70 \%)$ resolution of ST-segment elevation at 60 minutes after PCI.

Safety end points included major bleeding, life-threatening bleeding, and minor bleeding (excluding bleeding related to coronary-artery bypass grafting) within the first 48 hours and over the 30-day treatment period, evaluated with the use of PLATO (Study of Platelet Inhibition and Patient Outcomes), TIMI, STEEPLE (Safety and Efficacy of Enoxaparin in Percutaneous Coronary Intervention Patients), ISTH (International Society on Thrombosis and Haemostasis), GUSTO (Global Utilization of Streptokinase and Tissue Plasminogren Activator for Occluded Coronary Arteries), and BARC (Bleeding Academic Research Consortium) criteria. ${ }^{25}$

Centralized, blinded reviews of angiographic data and ECG recordings were conducted by Cardialysis Core Laboratory services (Rotterdam, the Netherlands) and eResearch Technology (ERT; Peterborough, United Kingdom), respectively. An independent adjudication committee, whose members were unaware of the treatment assignments, reviewed the clinical end points, except deaths and minimal bleeding events (see the Supplementary Appendix, available at NEJM.org).

\section{STUDY OVERSIGHT AND FUNDING}

The executive and steering committees (see the Supplementary Appendix) oversaw the conduct of the trial and data analysis, in collaboration with representatives of the study sponsor (AstraZeneca).
The trial was monitored by an independent data and safety monitoring board (see the Supplementary Appendix).

Data were collected and analyzed by Worldwide Clinical Trials (London) according to the protocol and the predefined statistical analysis plan. The chair of the executive committee (the first author) had unrestricted access to the data after the database was locked, and statistical analyses were performed independently by one of the academic authors, who is a statistician for the ACTION study group. The first author prepared the first draft of the manuscript; all the authors revised the manuscript and made the decision to submit it for publication. All the authors assume responsibility for the accuracy and completeness of the data and analyses reported and for the fidelity of the study to the protocol. Medical-writing support, funded by AstraZeneca, was provided by Prime Medica.

\section{STATISTICAL ANALYSIS}

We calculated that the study would have $80 \%$ power to detect a difference of 6 percentage points ( $40 \%$ relative difference) between the two groups in the complete resolution of ST-segment elevation, assuming a $15 \%$ rate of complete resolution in the control group (i.e., patients who received the initial loading dose of ticagrelor in the hospital). ${ }^{24}$ The study was also adequately powered to assess differences regarding TIMI flow before PCI. ${ }^{25}$

Efficacy analyses were performed in the modified intention-to-treat population, defined as all the patients who underwent randomization and received at least one dose of the study drug. Patients with missing data for either ST-segment elevation or TIMI flow grade were excluded from the analysis of the two coprimary end points. For each end point, the treatment groups were compared with the use of a logistic-regression model with treatment as an exploratory variable. A Holm procedure to correct for multiple comparisons, which included the adjustment of significance level and sequential testing, was used to control the overall type I error rate of $5 \%$ in testing the two coprimary end points.

Subgroup analyses to evaluate variations in treatment effect were performed with the use of the logistic-regression model and with terms for treatment, subgroup, and interaction of treatment with subgroup. P values were not adjusted for these analyses.

Secondary end points (clinical end points, reso- 


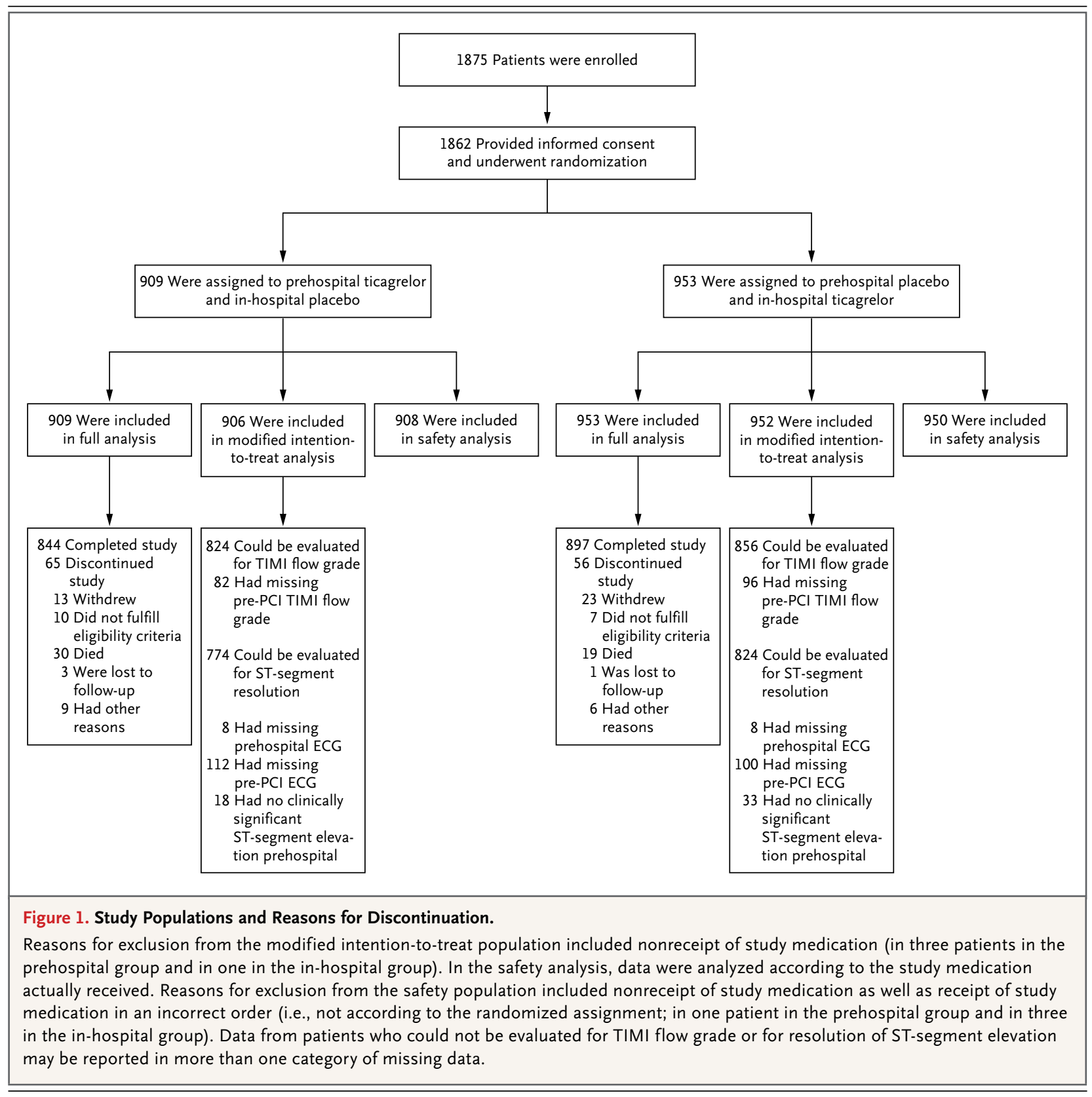

lution of ST-segment elevation or TIMI flow at the end of the procedure, and thrombotic bailout with glycoprotein IIb/IIIa inhibitors) were examined with the use of an analysis identical to that described for the coprimary end points. KaplanMeier estimates of clinical end points were also calculated for the first 30 days after the first dose. Since no prespecified hypothesis was made, statistical testing of all secondary efficacy variables, including the clinical end points, was considered to be exploratory, and no hierarchical rule for tests or adjustment was used.
The safety analysis included all the patients who received at least one dose of the study drug. Adjudicated bleeding events were summarized separately, according to the protocol definition (PLATO criteria) and other prespecified definitions.

\section{RESULTS}

\section{PATIENTS AND PROCEDURES}

Between September 12, 2011, and October 3, 2013, a total of 1875 patients were enrolled in the 
ATLANTIC study, of whom 1862 provided written informed consent and were randomly assigned to either prehospital ticagrelor (909 patients) or in-hospital ticagrelor (953 patients). Randomization was performed by 102 ambulance services, followed by transfer to 112 PCI centers in 13 countries (Table S1 in the Supplementary Appendix). Reasons for discontinuation and for exclusion from the analyses are shown in Figure 1.

The characteristics of the patients at baseline were well balanced between the two groups, with a numerically small, nonsignificant imbalance with respect to a TIMI risk score of more than 6 (Table 1, and Table S2 in the Supplementary Appendix). The first medical contact was in the ambulance for more than $75 \%$ of the patients; the first medical contact for the remaining patients was in an emergency department, before ambulance transfer. Coronary angiography was performed primarily by means of radial access

\section{Table 1. Demographic Characteristics and Treatment of the Patients at Baseline.*}

\section{Characteristic}

Age

Mean age $-\mathrm{yr}$

$\geq 75 \mathrm{yr}$ - no. (\%)

Female sex - no. (\%)

Body weight $-\mathrm{kg}$

$\mathrm{BMI} \geq 30$ - no. $(\%) \dagger$

Diabetes mellitus - no. (\%)

TIMI risk score - no. (\%)

$0-2$

3-6

$>6$

Killip class I - no. (\%)

First medical contact - no. (\%)』

In ambulance

In emergency department before ambulance transfer

Procedures for index event

Coronary angiography - no. (\%)

Femoral access - no./total no. (\%)

Radial access - no./total no. (\%)

Missing data - no./total no. (\%)

Thromboaspiration — no. (\%)

$\mathrm{PCl}$ - no. (\%)

With stent 9

Drug-eluting stent

Bare-metal stent

Without stent

CABG - no. (\%)

No $\mathrm{PCl}$ or $\mathrm{CABG}$ - no. (\%)

Study medication - no. (\%)

First loading dose

Second loading dose

Maintenance dose

\section{Prehospital Ticagrelor} $(\mathrm{N}=909)$

$60.6 \pm 12.4$

$144(15.8)$

$173(19.0)$

$80.4 \pm 15.9$

177 (19.5)

$115(12.7)$

$552(60.7)$

$337(37.1)$

$20(2.2)$

$819(90.1)$

$689(75.8)$

$220(24.2)$

890 (97.9)

$280 / 890$ (31.5)

$604 / 890$ (67.9)

$6 / 890(0.7)$

$471(51.8)$

$800(88.0)$

$760(83.6)$

$467(51.4)$

$305(33.6)$

$40(4.4)$

$10(1.1)$

99 (10.9)

905 (99.6)

$864(95.0)$

784 (86.2)
In-Hospital Ticagrelor ( $N=953)$

$61.0 \pm 12.5$

160 (16.8)

$196(20.6)$

$79.7 \pm 15.6$

178 (18.7)

$138(14.5)$

$573(60.1)$

365 (38.3)

15 (1.6)

$862(90.5)$

723 (75.9)

$229(24.0)$

937 (98.3)

$309 / 937$ (33.0)

$625 / 937$ (66.7)

$3 / 937(0.3)$

$470(49.3)$

830 (87.1)

$776(81.4)$

$479(50.3)$

$312(32.7)$

54 (5.7)

$15(1.6)$

$108(11.3)$

952 (99.9)

$908(95.3)$

809 (84.9) 


\begin{tabular}{|c|c|c|c|}
\hline & Characteristic & $\begin{array}{l}\text { Prehospital Ticagrelor } \\
\qquad(\mathrm{N}=909)\end{array}$ & $\begin{array}{l}\text { In-Hospital Ticagrelor } \\
\qquad(\mathrm{N}=953)\end{array}$ \\
\hline \multicolumn{4}{|c|}{ Aspirin - no. (\%) } \\
\hline & Any use & $898(98.8)$ & $938(98.4)$ \\
\hline & Maintenance dose & $843(92.7)$ & $880(92.3)$ \\
\hline \multicolumn{4}{|c|}{ Other antithrombotic medication for index event — no. (\%) } \\
\hline & Glycoprotein IIb/IIla inhibitor before PCI\| & $274(30.1)$ & $259(27.2)$ \\
\hline & Intravenous anticoagulant during hospitalization & $791(87.0)$ & $851(89.3)$ \\
\hline & Heparin & $607(66.8)$ & $654(68.6)$ \\
\hline & Enoxaparin & $247(27.2)$ & $253(26.5)$ \\
\hline & Bivalirudin & $175(19.3)$ & $190(19.9)$ \\
\hline & Fondaparinux & $51(5.6)$ & $63(6.6)$ \\
\hline & Combination therapy*** & $274(30.1)$ & $286(30.0)$ \\
\hline \multicolumn{4}{|c|}{$\begin{array}{l}\text { Plus-minus values are means } \pm \text { SD. There were no significant between-group differences in the baseline characteris- } \\
\text { tics listed here. For further details, see Table } S 2 \text { in the Supplementary Appendix. CABG denotes coronary-artery by- } \\
\text { pass grafting, and } \mathrm{PCI} \text { percutaneous coronary intervention. } \\
\text { The body-mass index (BMI) is the weight in kilograms divided by the square of the height in meters. } \\
\text { Thrombolysis in Myocardial Infarction (TIMI) risk scores assess the prognosis for patients with acute coronary syn- } \\
\text { dromes on a scale from } 0 \text { to } 14 \text {, with higher scores indicating greater risk. } \\
\text { The location of care at the time of randomization was unknown for one patient in the in-hospital group. First medical } \\
\text { contact was defined as occurring either in the ambulance (primary transfer to an appropriate hospital setting) or in } \\
\text { an emergency department before ambulance transfer (secondary transfer to an appropriate hospital setting). } \\
\text { Patients may have received more than one type of stent. } \\
\text { Data on glycoprotein IIb/IIIa inhibitor use (before and after PCI) were missing for two patients in the prehospital group. } \\
\text { Combination therapy was defined as a sequence of prescriptions for different anticoagulants, with changes in antico- } \\
\text { agulant use during the hospitalization phase. }\end{array}$} \\
\hline
\end{tabular}

(in $67.3 \%$ of the patients who underwent coronary angiography), and PCI was performed in $87.5 \%$ of the patients (Table 1 ).

The median times from symptom onset to STEMI diagnosis, from randomization to angiography, and between the two loading doses (i.e., prehospital vs. in-hospital), were 73,48 , and 31 minutes, respectively (Fig. S1 in the Supplementary Appendix). The first and second loading doses of study medication were administered to more than $99 \%$ and $95 \%$ of the patients, respectively, and nearly $99 \%$ received at least one dose of aspirin (Table 1). The majority of patients with STEMI received maintenance treatment with ticagrelor $(85.6 \%$ of patients) and aspirin $(92.5 \%)$. Just over one third of patients received a glycoprotein IIb/IIIa inhibitor.

\section{EFFICACY}

Platelet reactivity was reduced significantly and progressively after the administration of ticagrelor in both study groups in the pharmacodynamic substudy, which included 37 patients. There was no significant difference between prehospital and in-hospital administration of ticagrelor at any time point, with the maximum numerical difference between the treatment groups being observed 1 hour after PCI (Fig. S2 and S3 in the Supplementary Appendix).

There was no significant difference between the prehospital group and the in-hospital group in terms of the proportion of patients who did not have a $70 \%$ or greater resolution of ST-segment elevation before PCI (odds ratio with prehospital vs. in-hospital administration of the loading dose of ticagrelor, 0.93 ; 95\% confidence interval [CI], 0.69 to $1.25 ; \mathrm{P}=0.63$ ) and the proportion of $\mathrm{pa}-$ tients who did not have a TIMI flow of grade 3 in the infarct-related artery at initial angiography (odds ratio, $0.97 ; 95 \% \mathrm{CI}, 0.75$ to $1.25 ; \mathrm{P}=0.82$ ) (Table 2). The absence of $70 \%$ or greater resolution of ST-segment elevation 1 hour after PCI was reported for $42.5 \%$ of patients in the prehospital group and $47.5 \%$ of those in the in-hospital group ( $\mathrm{P}=0.055)$, and the absence of TIMI flow grade 3 in the culprit artery was reported for 


\begin{tabular}{|c|c|c|c|c|c|}
\hline \multirow[t]{2}{*}{ End Point } & $\begin{array}{l}\text { Prehospital } \\
\text { Ticagrelor } \\
(\mathrm{N}=906)\end{array}$ & $\begin{array}{l}\text { In-Hospital } \\
\text { Ticagrelor } \\
(\mathrm{N}=952)\end{array}$ & $\begin{array}{l}\text { Odds Ratio } \\
(95 \% \mathrm{Cl}) \dagger\end{array}$ & P Value & $\begin{array}{l}\text { Difference } \\
(95 \% \mathrm{Cl}) \div\end{array}$ \\
\hline & \multicolumn{5}{|c|}{$\begin{array}{l}\text { no./no. of patients who could be } \\
\text { evaluated (\%) }\end{array}$} \\
\hline \multicolumn{6}{|l|}{ Coprimary end points } \\
\hline $\begin{array}{l}\text { Absence of ST-segment elevation resolu- } \\
\text { tion } \geq 70 \% \text { before } \mathrm{PCl}\end{array}$ & $672 / 774(86.8)$ & $722 / 824(87.6)$ & 0.93 (0.69 to 1.25$)$ & 0.63 & $-0.008(-0.041$ to 0.025$)$ \\
\hline $\begin{array}{l}\text { Absence of TIMI flow grade } 3 \text { in infarct- } \\
\text { related artery at initial angiography }\end{array}$ & $681 / 824(82.6)$ & $711 / 856(83.1)$ & 0.97 (0.75 to 1.25$)$ & 0.82 & $-0.004(-0.040$ to 0.032$)$ \\
\hline \multicolumn{6}{|l|}{ Met one or both coprimary end points } \\
\hline Both & $541 / 744$ (72.7) & $571 / 777(73.5)$ & $0.96(0.77$ to 1.21$)$ & 0.73 & $-0.008(-0.052$ to 0.037$)$ \\
\hline One or both & $677 / 719(94.2)$ & $710 / 751(94.5)$ & $0.93(0.60$ to 1.45$)$ & 0.75 & $-0.004(-0.027$ to 0.020$)$ \\
\hline \multicolumn{6}{|l|}{ Secondary end points } \\
\hline $\begin{array}{l}\text { Absence of ST-segment elevation resolu- } \\
\text { tion } \geq 70 \% \text { after } \mathrm{PCl}\end{array}$ & $303 / 713(42.5)$ & $353 / 743(47.5)$ & $0.82(0.66$ to 1.004$)$ & 0.05 & $-0.050(-0.101$ to 0.001$)$ \\
\hline $\begin{array}{l}\text { Absence of TIMI flow grade } 3 \text { in infarct } \\
\text { related artery after PCI }\end{array}$ & $135 / 760(17.8)$ & $154 / 784(19.6)$ & 0.88 (0.68 to 1.14$)$ & 0.34 & $-0.019(-0.058$ to 0.020$)$ \\
\hline \multicolumn{6}{|l|}{ Met one or both secondary end points } \\
\hline Both & $73 / 763(9.6)$ & $87 / 775(11.2)$ & 0.84 (0.60 to 1.16$)$ & 0.29 & $-0.017(-0.047$ to 0.014$)$ \\
\hline One or both & $339 / 684(49.6)$ & $371 / 703(52.8)$ & 0.88 (0.71 to 1.09$)$ & 0.23 & $-0.032(-0.085$ to 0.020$)$ \\
\hline
\end{tabular}

* Data include the total number of patients who had data that could be evaluated. Data were missing as follows: TIMI flow grade for 178 patients ( 82 patients in the prehospital group and 96 in the in-hospital group), prehospital ST-segment elevation for 16 ( 8 in each treatment group), and pre-PCI ST-segment elevation for 212 (112 in the prehospital group and 100 in the in-hospital group). Before arrival at the hospital, 51 patients had no clinically significant ST elevation and therefore could not be evaluated for resolution of ST-segment elevation (18 patients in the prehospital group and 33 in the in-hospital group). ST-segment resolution was calculated as the combination of two electrocardiographic (ECG) variables (ST segment at index ECG and ST segment before PCI).

$\uparrow$ The odds ratios for the prehospital group versus the in-hospital group, two-sided $95 \%$ confidence intervals, and $\mathrm{P}$ values were calculated from a logistic-regression model, with treatment as the only explanatory variable.

$\uparrow$ The difference in binomial proportions was calculated as the proportion in the prehospital group minus the proportion in the in-hospital group.

$17.8 \%$ and $19.6 \%$ of the patients, respectively $(\mathrm{P}=0.34)$. The results were consistent across quartiles of time from the first loading dose to the ECG or angiogram obtained before PCI, corresponding to different transfer times (data not shown). The results were also consistent for both coprimary end points across prespecified subgroups, except for the subgroup of patients in whom morphine was administered (Fig. S4 in the Supplementary Appendix). The primary end point of ST-segment resolution was significantly improved with prehospital administration of ticagrelor in patients not receiving morphine ( $\mathrm{P}=0.005$ for interaction).

There were no significant differences between the two groups for the composite end point of death, myocardial infarction, stroke, urgent coronary revascularization, or stent thrombosis (Fig. S5 in the Supplementary Appendix). However, definite stent thrombosis was reduced in the prehospital group both at 24 hours (0 of 906 patients [0\%] in the prehospital group vs. 8 of 952 [0.8\%] in the in-hospital group, $\mathrm{P}=0.008$ by Fisher's exact test) and at 30 days (2 of 906 [0.2\%] vs. 11 of 952 [1.2\%], $\mathrm{P}=0.02$ ) (Fig. 2 and Table 3). There was no clear relationship between type of anticoagulation and the occurrence of stent thrombosis (Table S3 in the Supplementary Appendix).

A total of 30 patients $(3.3 \%)$ in the prehospital group and 19 (2.0\%) in the in-hospital group died $(\mathrm{P}=0.08)$. The most common causes of death were cardiogenic shock, cardiac arrest, mechanical complication, and heart failure (Table S4 in the Supplementary Appendix).

\section{SAFETY}

Rates of bleeding events that were not related to coronary-artery bypass grafting were low during the first 48 hours after the initial dose and from 
48 hours through 30 days, and the rates did not differ significantly between the two study groups (Table 3). The results were consistent across all the definitions and types of bleeding adjudicated by the clinical end-point committee (Table $\mathrm{S} 5$ in the Supplementary Appendix). There was no significant difference in the rates of bleeding events between the two study groups among the $11.1 \%$ of patients who did not undergo revascularization or among the $8.6 \%$ of patients who did not have a final diagnosis of STEMI. There was no imbalance between the two treatment groups in terms of serious adverse events.

\section{DISCUSSION}

Prehospital treatment of ongoing STEMI with fibrinolytic agents or glycoprotein IIb/IIIa inhibitors has been associated with improved coronary reperfusion and outcomes. ${ }^{6,8,26-29}$ The present study shows that the administration of the potent $\mathrm{P} 2 \mathrm{Y}_{12}$-receptor antagonist ticagrelor shortly before PCI does not improve reperfusion of the culprit artery before the procedure but is safe and may prevent postprocedural acute stent thrombosis. The observed preventive benefit is consistent with pharmacodynamic and ECG findings suggesting that the maximal effect of prehospital administration of ticagrelor occurs after the end of the procedure.

Pretreatment (i.e., before coronary angiography) with glycoprotein IIb/IIIa inhibitors or $\mathrm{P}_{12} \mathrm{Y}_{12}$-receptor antagonists in patients with nonST-segment elevation (NSTE) acute coronary syndromes has been associated with excess bleeding, without a reduction in ischemic complications, ${ }^{18,30,31}$ leading to guideline recommendations against the use of these agents in such patients. $^{32,33}$ There is limited information on pretreatment with clopidogrel in patients with STEMI undergoing PCI, but the available data suggest that there is no safety issue and that the rate of major adverse cardiovascular events may be reduced. ${ }^{14,15}$ The ATLANTIC study shows that the early administration of ticagrelor in patients with STEMI is safe, regardless of the definition of bleeding used. This favorable safety profile may be related to the high likelihood of both confirmation of the diagnosis of STEMI and treatment with PCI and placement of a stent; in contrast, the diagnosis of NSTE acute coronary syndrome in patients presenting with transient

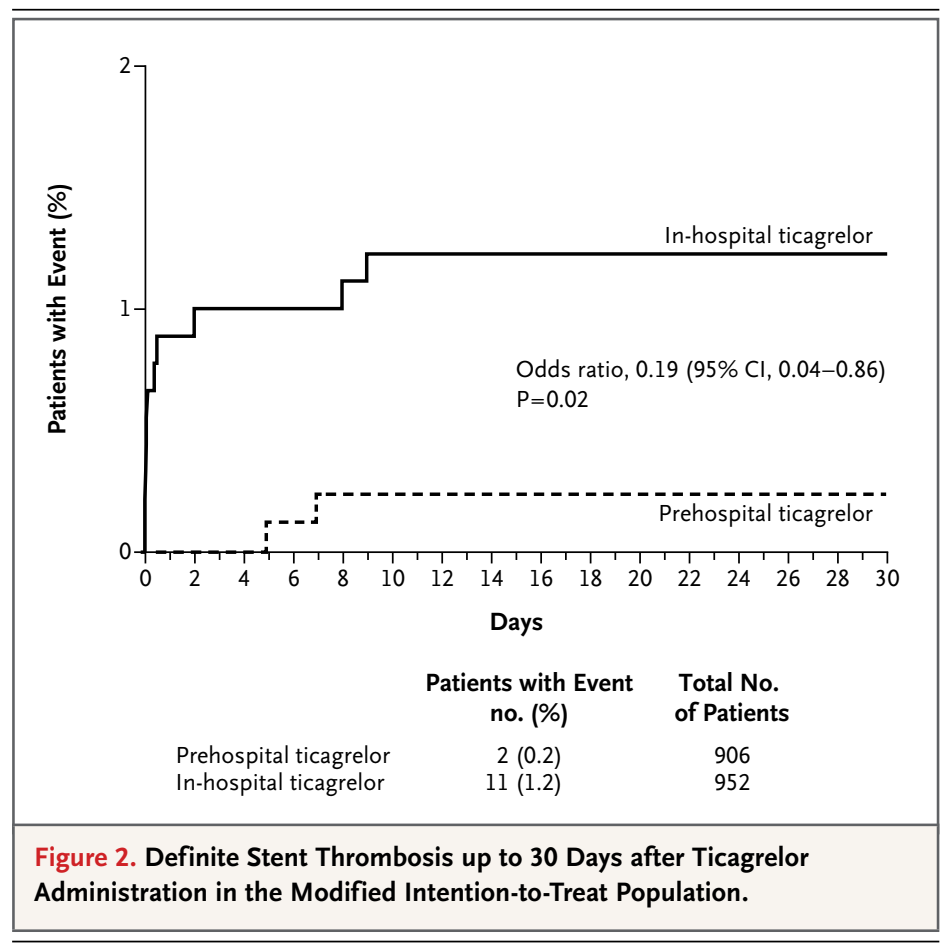

chest pain is often not confirmed, and PCI is not performed in 30 to $60 \%$ of such patients. ${ }^{34,35}$

The rate of stent thrombosis was reduced with prasugrel or ticagrelor in the STEMI cohorts in the pivotal trials comparing these agents with clopidogrel $^{1,36}$; whether earlier administration of these drugs could further reduce the risk was unknown. In this study, all the stent-thrombosis events within the first 24 hours occurred in the in-hospital group, and the difference remained significant in favor of prehospital administration of ticagrelor for up to 30 days. Although our platelet-reactivity results lack statistical power, the maximal difference in platelet inhibition occurred concomitantly with the reduction of stent thrombosis, the findings being supportive of one another. Stent thrombosis has been under scrutiny, and the excess of early stent-thrombosis events observed consistently across trials with bivalirudin $^{37-39}$ has been seen largely as a reason for limiting its use. In our study, the rate of definite stent thrombosis was reduced without a safety trade-off. Although prespecified, stent thrombosis was a secondary end point among neutral study results; therefore, this finding should not be interpreted as definitive.

Mortality was reduced with ticagrelor, as compared with clopidogrel, in the large PLATO 


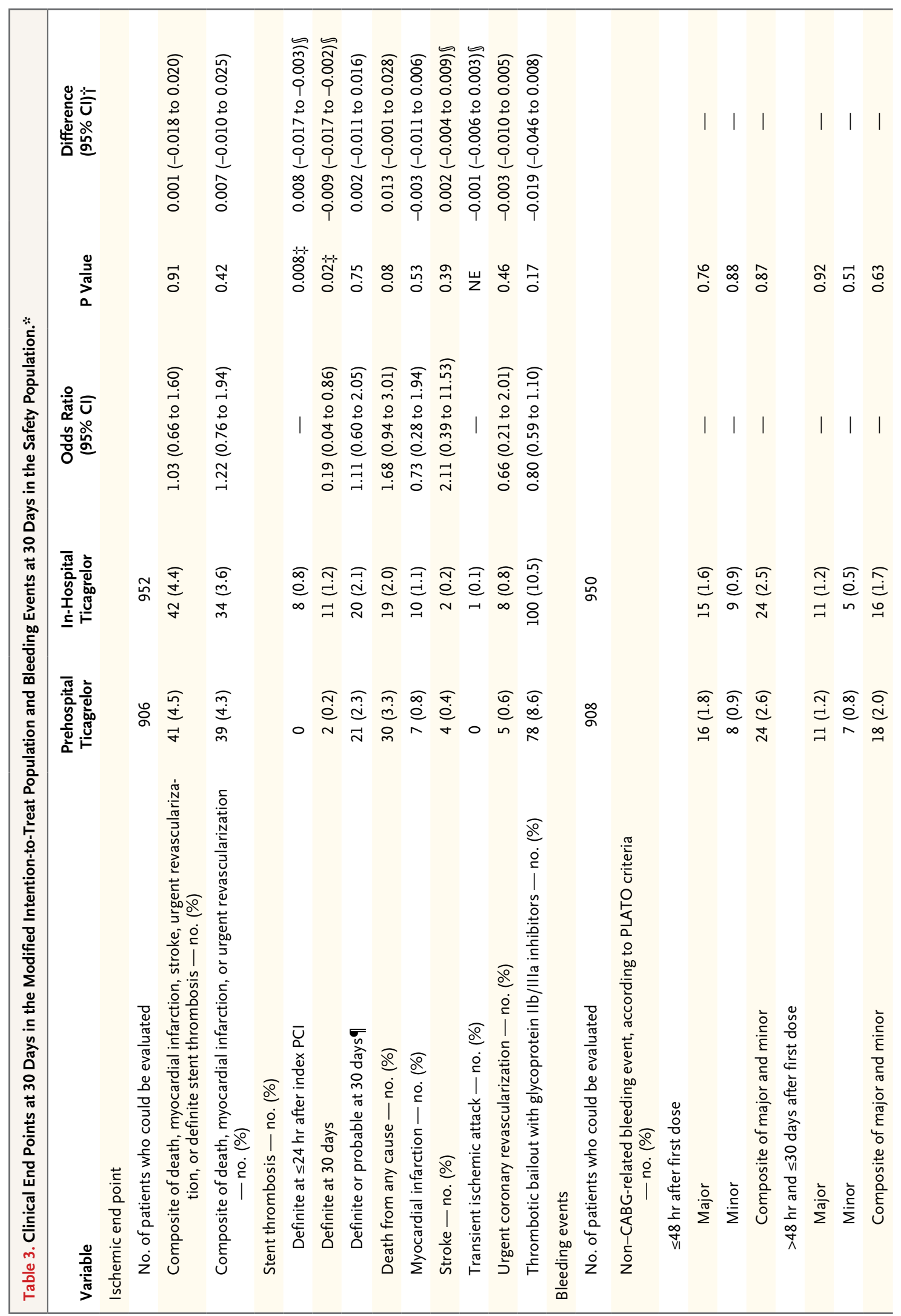




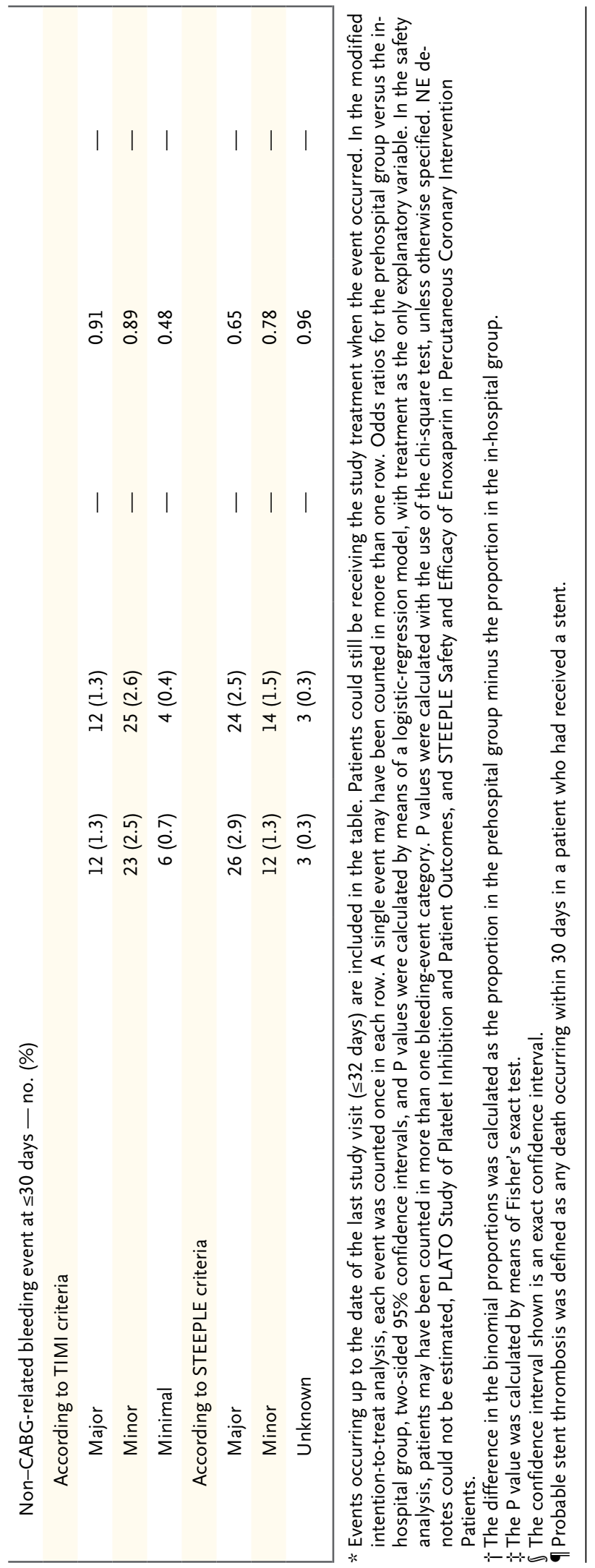

trial. ${ }^{23}$ In the ATLANTIC trial, mortality was low and there was a nonsignificant numerical excess of deaths in the prehospital group. Almost all the deaths were due to cardiogenic shock, cardiac arrest, or cardiac rupture rather than to bleeding or ischemic events. This finding may reflect the fact that ambulance crews did not exclude the sickest patients from the study, and we cannot rule out an imbalance between the two study groups in terms of the severity of the presenting event (e.g., a higher TIMI risk score in the prehospital group).

Our study has limitations inherent in the sample size and the short intervals between administration of the study drug and reperfusion. There is consistency across the data on pharmacodynamics, ST-segment resolution, and TIMI flow grade, which suggests that most of the drug effect occurred after PCI. The time to PCI in our study was extremely short in both groups, indicating excellent practice, but this may have blunted the drug effect and may not reflect routine practice. Another potential limitation is related to the delayed absorption of orally administered $\mathrm{P}_{2} \mathrm{Y}_{12}$-receptor antagonists. ${ }^{19-21}$ The onset of action may have been delayed further by morphine coadministration in half the study population. ${ }^{21,40}$ Patients who did not receive morphine had a significant improvement in the ECG-based primary end point, with a significant $\mathrm{P}$ value for interaction between morphine use and time of ticagrelor administration. The extent to which this interaction may have affected our results remains unknown at this stage.

In conclusion, prehospital administration of ticagrelor a short time before PCI in patients presenting with ongoing STEMI appeared to be safe but did not improve pre-PCI coronary reperfusion.

\footnotetext{
Supported by AstraZeneca.

Dr. Montalescot reports receiving consulting fees from Bayer, Boehringer Ingelheim, Cardiovascular Research Foundation, Europa Organisation, the Gerson Lehrman Group, Iroko Cardio International, Lead-Up, Luminex, McKinsey and Company, Remedica, Servier, the TIMI Study Group, WebMD, Wolters Kluwer Health, Bristol-Myers Squibb, AstraZeneca, Biotronik, Eli Lilly, the Medicines Company, Menarini Group, Roche, Sanofi-Aventis, Pfizer, Daiichi-Sankyo, and Medtronic and grant support from Bristol-Myers Squibb, AstraZeneca, Biotronik, Eli Lilly, the Medicines Company, Menarini, Sanofi-Aventis, Pfizer, Roche, Accumetrics, Medtronic, Abbott Laboratories, Daiichi-Sankyo, Nanosphere, and Stentys. Dr. van 't Hof reports receiving consulting fees from the Medicines Company, Eli Lilly, and Daiichi-Sankyo, lecture fees from the Medicines Company, Eli Lilly, Daiichi-Sankyo, Medtronic, and Correvio, and grant support from the Medicines Company, Eli Lilly, Daiichi-Sankyo, Medtronic, Abbott Laboratories, and Correvio. Dr. Lapostolle reports receiving
} 
honoraria from Boehringer Ingelheim, Bayer, the Medicines Company, Correvio, Daiichi-Sankyo, and Eli Lilly and lecture fees and grant support from Merck Serono, Roche, Boehringer Ingelheim, Bayer, the Medicines Company, Correvio, DaiichiSankyo, and Eli Lilly. Dr. Silvain reports receiving consulting fees from AstraZeneca, Daiichi-Sankyo, Eli Lilly, the Medicines Company, Bristol-Myers Squibb, Boehringer Ingelheim, and Iroko Cardio International and lecture fees from AstraZeneca, Daiichi-Sankyo, Eli Lilly, the Medicines Company, Bristol-Myers Squibb, Boehringer Ingelheim, and Iroko Cardio International, Stentys, and Servier. Dr. Lassen, Dr. Cantor, and Dr. Willems report receiving lecture fees from AstraZeneca. Dr. Bolognese reports receiving consulting and lecture fees and fees for board membership from Daiichi-Sankyo, Eli Lilly, Menarini, Abbott Laboratories, AstraZeneca, and Iroko Cardio International. Dr. Cequier reports receiving consulting fees from AstraZeneca, Abbott Laboratories, Medtronic, Boston Scientific, Ferrer, DaiichiSankyo, and Eli Lilly, lecture fees from AstraZeneca, DaiichiSankyo, Eli Lilly, and Servier, and grant support from AstraZeneca, Abbott Laboratories, and Medtronic. Dr. Goodman reports receiving consulting fees, lecture fees, and grant support through his institution from AstraZeneca, Eli Lilly, and Sanofi-Aventis. Dr. Hammett reports receiving consulting fees from AstraZeneca, Eli Lilly, Bayer, Boehringer Ingelheim, Amgen, and the Medicines Company and lecture fees from AstraZeneca, Eli Lilly, Bayer, and Boehringer Ingelheim. Dr. Storey reports receiving honoraria from AstraZeneca, Correvio, Daiichi-Sankyo, Eli Lilly, Merck, Roche, Regeneron, Sanofi-Aventis, the Medicines Company, and Medscape, consulting fees from AstraZeneca, Accumetrics, Novartis, and PlaqueTec, lecture fees from AstraZeneca and Accumet- rics, travel support from AstraZeneca, and grant support from AstraZeneca, Accumetrics, Daiichi-Sankyo, Eli Lilly, and Merck. Dr. Zeymer reports receiving honoraria and speaker fees from AstraZeneca, Daiichi-Sankyo, Eli Lilly, Bayer, the Medicines Company, Sanofi-Aventis, Novartis, Boehringer Ingelheim, and Merck Sharp and Dohme and grant support from Daiichi-Sankyo, Eli Lilly, Sanofi-Aventis, and Novartis. Dr. Ecollan reports receiving consulting fees from Abbott Laboratories, Eli Lilly, AstraZeneca, Sanofi-Aventis, and bioMérieux. Dr. Collet reports receiving consulting fees from Sanofi-Aventis, lecture fees from Daiichi-Sankyo, Bristol-Myers Squibb, and AstraZeneca, and grant support from Bristol-Myers Squibb and Medtronic. Ms. Baradat, Ms. Licour, and Dr. Tsatsaris are employees of AstraZeneca. Dr. Vicaut reports receiving fees for serving on a data and safety monitoring board at the European Cardiovascular Research Center, consulting fees from Abbott Laboratories, Bristol-Myers Squibb, Celgene, Fresenius, LFB, Eli Lilly, Medtronic, Pfizer, and Sanofi-Aventis, lecture fees from Novartis, and grant support from Boehringer Ingelheim and Sanofi-Aventis. Dr. Hamm reports receiving lecture fees from Daiichi-Sankyo, Correvio, and Sanofi-Aventis and grant support from AstraZeneca. No other potential conflict of interest relevant to this article was reported.

Disclosure forms provided by the authors are available with the full text of this article at NEJM.org.

We thank Liz Anfield of Prime Medica (Knutsford, Cheshire) for medical writing support, Richard Cairns of Worldwide Clinical Trials (London) for statistical analysis, Néjoua Salhi for medical support, Sylvie Barret for data-management support, and all the patients who took part in this study.

\section{APPENDIX}

The authors' affiliations are as follows: Allies in Cardiovascular Trials Initiatives and Organized Networks (ACTION) Study Group, Institut de Cardiologie, Assistance Publique-Hôpitaux de Paris (AP-HP), Centre Hospitalier Universitaire (CHU) Pitié-Salpêtrière, INSERM Unité Mixte de Recherche Scientifique 1166, Université Paris 6 (G.M., J.S., J.-P.C.), Service Medical d'Urgence, Brigade de Sapeurs Pompiers de Paris (O.S.), Service Mobile d'Urgence et de Réanimation, CHU Pitié-Salpêtrière AP-HP (P.E.), and the ACTION Study Group, Unité de Recherche Clinique, Hôpital Lariboisière (E.V.), Paris, Service d'Aide Médicale Urgente 93, Hôpital Avicenne, Bobigny (F.L.), and AstraZeneca, Rueil Malmaison (C.B., M.L., A.T.) - all in France; the Department of Cardiology, Isala Clinics, Zwolle (A.W.H.), and Regionale Ambulance Voorziening Gelderland-Midden (W.M.J.M.H.) and the Department of Cardiology, Rijnstate Ziekenhuis (F.F.W.), Arnheim - all in the Netherlands; the Department of Cardiology B, Aarhus University Hospital, Skejby, Aarhus, Denmark (J.F.L.); the Cardiovascular and Neurologic Department, Azienda Ospedaliera Arezzo, Arezzo, Italy (L.B.); Southlake Regional Health Centre (W.J.C.) and Canadian Heart Research Centre, Division of Cardiology, St Michael's Hospital (S.G.G.), University of Toronto, Toronto; the Heart Disease Institute, Hospital Universitario de Bellvitge, University of Barcelona, L'Hospitalet de Llobregat, Barcelona (A.C.); Centre Hospito-universitaire Franz Fanon, Blida, Algeria (M.C.); the Department of Cardiology, Royal Brisbane and Women's Hospital, Brisbane, QLD, Australia (C.J.H.); the Third Department of Medicine, Cardiology and Intensive Care Medicine, Wilhelminenspital, Vienna (K.H.); the Departments of Cardiology and Medical and Health Sciences, Linköping University, Linköping, Sweden (M.J., E.S.); the Heart and Vascular Center, Semmelweis University, Budapest, Hungary (B.M.); the Department of Cardiovascular Science, University of Sheffield, Sheffield, United Kingdom (R.F.S.); and Klinikum Ludwigshafen and Institut für Herzinfarktforschung Ludwigshafen, Ludwigshafen (U.Z.), and the Department of Cardiology, Kerckhoff Heart Center, Bad Nauheim (C.W.H.) — both in Germany.

\section{REFERENCES}

1. Montalescot G, Wiviott SD, Braunwald E, et al. Prasugrel compared with clopidogrel in patients undergoing percutaneous coronary intervention for ST-elevation myocardial infarction (TRITON-TIMI 38): double-blind, randomised controlled trial. Lancet 2009;373:723-31.

2. Steg PG, James S, Harrington RA, et al. Ticagrelor versus clopidogrel in patients with ST-elevation acute coronary syndromes intended for reperfusion with primary percutaneous coronary intervention: a Platelet Inhibition and Patient Outcomes (PLATO) trial subgroup analysis. Circulation 2010;122:2131-41.

3. Bellemain-Appaix A, Brieger D, Beygui F, et al. New P2Y12 inhibitors ver- sus clopidogrel in percutaneous coronary intervention: a meta-analysis. J Am Coll Cardiol 2010;56:1542-51.

4. Bhatt DL, Lincoff AM, Gibson CM, et al. Intravenous platelet blockade with cangrelor during PCI. N Engl J Med 2009; 361:2330-41.

5. Bhatt DL, Stone GW, Mahaffey KW, et al. Effect of platelet inhibition with cangrelor during PCI on ischemic events. N Engl J Med 2013;368:1303-13.

6. Montalescot G, Barragan P, Wittenberg O, et al. Platelet glycoprotein IIb/IIIa inhibition with coronary stenting for acute myocardial infarction. N Engl J Med 2001;344:1895-903.

7. Herrmann HC, Lu J, Brodie BR, et al.
Benefit of facilitated percutaneous coronary intervention in high-risk ST-segment elevation myocardial infarction patients presenting to nonpercutaneous coronary intervention hospitals. JACC Cardiovasc Interv 2009;2:917-24.

8. Van't Hof AW, Ten Berg J, Heestermans T, et al. Prehospital initiation of tirofiban in patients with ST-elevation myocardial infarction undergoing primary angioplasty (On-TIME 2): a multicentre, doubleblind, randomised controlled trial. Lancet 2008;372:537-46.

9. ten Berg JM, van 't Hof AW, Dill T, et al. Effect of early, pre-hospital initiation of high bolus dose tirofiban in patients with ST-segment elevation myocardial infarc- 
tion on short- and long-term clinical outcome. J Am Coll Cardiol 2010;55:2446-55. 10. De Luca G, Navarese E, Marino P. Risk profile and benefits from Gp IIb-IIIa inhibitors among patients with ST-segment elevation myocardial infarction treated with primary angioplasty: a meta-regression analysis of randomized trials. Eur Heart J 2009;30:2705-13.

11. Huber K, Holmes DR Jr, van 't Hof AW, et al. Use of glycoprotein IIb/IIIa inhibitors in primary percutaneous coronary intervention: insights from the APEX-AMI trial. Eur Heart J 2010;31:1708-16.

12. Stone GW, Grines CL, Cox DA, et al. Comparison of angioplasty with stenting, with or without abciximab, in acute myocardial infarction. N Engl J Med 2002; 346:957-66.

13. Ellis SG, Tendera M, de Belder MA, et al. Facilitated PCI in patients with STelevation myocardial infarction. $\mathrm{N}$ Engl $\mathrm{J}$ Med 2008;358:2205-17.

14. Zeymer U, Arntz HR, Mark B, et al. Efficacy and safety of a high loading dose of clopidogrel administered prehospitally to improve primary percutaneous coronary intervention in acute myocardial in farction: the randomized CIPAMI trial. Clin Res Cardiol 2012;101:305-12.

15. Bellemain-Appaix A, O'Connor SA, Silvain J, et al. Association of clopidogre pretreatment with mortality, cardiovascular events, and major bleeding among patients undergoing percutaneous coronary intervention: a systematic review and meta-analysis. JAMA 2012;308:2507-16. [Erratum, JAMA 2013;309:1461.]

16. Sabatine MS, Cannon CP, Gibson CM, et al. Effect of clopidogrel pretreatment before percutaneous coronary intervention in patients with ST-elevation myocardial infarction treated with fibrinolytics: the PCI-CLARITY study. JAMA 2005;294: 1224-32.

17. Storey RF, Angiolillo DJ, Patil SB, et al. Inhibitory effects of ticagrelor compared with clopidogrel on platelet function in patients with acute coronary syndromes: the PLATO (PLATelet inhibition and patient Outcomes) PLATELET substudy. J Am Coll Cardiol 2010;56:1456-62. 18. Montalescot G, Bolognese L, Dudek $\mathrm{D}$, et al. Pretreatment with prasugrel in non-ST-segment elevation acute coronary syndromes. N Engl J Med 2013;369:9991010.

19. Valgimigli M, Tebaldi M, Campo G, et al. Prasugrel versus tirofiban bolus with or without short post-bolus infusion with or without concomitant prasugrel admin istration in patients with myocardial in farction undergoing coronary stenting: the FABOLUS PRO (Facilitation through Aggrastat By drOpping or shortening Infusion Line in patients with ST-segment elevation myocardial infarction compared to or on top of PRasugrel given at loading dOse) trial. JACC Cardiovasc Interv 2012;5:268-77.
20. Alexopoulos D, Xanthopoulou I, Gkizas V, et al. Randomized assessment of ticagrelor versus prasugrel antiplatelet effects in patients with ST-segmentelevation myocardial infarction. Circ Cardiovasc Interv 2012;5:797-804.

21. Parodi G, Valenti R, Bellandi B, et al. Comparison of prasugrel and ticagrelor loading doses in ST-segment elevation myocardial infarction patients: RAPID (Rapid Activity of Platelet Inhibitor Drugs) primary PCI study. J Am Coll Cardiol 2013;61:1601-6.

22. Storey RF, Husted S, Harrington RA, et al. Inhibition of platelet aggregation by AZD6140, a reversible oral $\mathrm{P}_{12}$ receptor antagonist, compared with clopidogrel in patients with acute coronary syndromes. J Am Coll Cardiol 2007;50:1852-6.

23. Wallentin L, Becker RC, Budaj A, et al. Ticagrelor versus clopidogrel in patients with acute coronary syndromes. $\mathrm{N}$ Engl J Med 2009;361:1045-57.

24. Deeks ED. Ticagrelor: a review of its use in the management of acute coronary syndromes. Drugs 2011;71:909-33.

25. Montalescot G, Lassen JF, Hamm CW, et al. Ambulance or in-catheterization laboratory administration of ticagrelor for primary percutaneous coronary intervention for ST-segment elevation myocardial infarction: rationale and design of the randomized, double-blind Administration of Ticagrelor in the cath Lab or in the Ambulance for New ST elevation myocardial Infarction to open the Coronary artery (ATLANTIC) study. Am Heart J 2013;165:515-22.

26. Morrison LJ, Verbeek PR, McDonald AC, Sawadsky BV, Cook DJ. Mortality and prehospital thrombolysis for acute myocardial infarction: a meta-analysis. JAMA 2000;283:2686-92.

27. Westerhout CM, Bonnefoy E, Welsh RC, Steg PG, Boutitie F, Armstrong PW. The influence of time from symptom onset and reperfusion strategy on 1-year survival in ST-elevation myocardial infarction: a pooled analysis of an early fibrinolytic strategy versus primary percutaneous coronary intervention from CAPTIM and WEST. Am Heart J 2011;161:283-90.

28. Montalescot G, Borentain M, Payot L, Collet JP, Thomas D. Early vs late administration of glycoprotein IIb/IIIa inhibitors in primary percutaneous coronary intervention of acute ST-segment elevation myocardial infarction: a meta-analysis. JAMA 2004;292:362-6.

29. De Luca G, Gibson CM, Bellandi F, et al. Early glycoprotein IIb-IIIa inhibitors in primary angioplasty (EGYPT) cooperation: an individual patient data metaanalysis. Heart 2008;94:1548-58.

30. Stone GW, Bertrand ME, Moses JW, et al. Routine upstream initiation vs deferred selective use of glycoprotein IIb/ IIIa inhibitors in acute coronary syndromes: the ACUITY Timing trial. JAMA 2007;297:591-602.
31. Giugliano RP, White JA, Bode C, et al. Early versus delayed, provisional eptifibatide in acute coronary syndromes. $\mathrm{N}$ Engl J Med 2009;360:2176-90.

32. Anderson JL, Adams CD, Antman EM, et al. 2012 ACCF/AHA focused update incorporated into the ACCF/AHA 2007 guidelines for the management of patients with unstable angina/non-ST-elevation myocardial infarction: a report of the American College of Cardiology Foundation/American Heart Association Task Force on Practice Guidelines. Circulation 2013;127(23):e663-e828. [Erratum, Circulation 2013;127(24):e863-e864.]

33. Hamm CW, Bassand J-P, Agewall S, et al. ESC guidelines for the management of acute coronary syndromes in patients presenting without persistent ST-segment elevation: the Task Force for the management of acute coronary syndromes (ACS) in patients presenting without persistent ST-segment elevation of the European Society of Cardiology (ESC). Eur Heart J 2011;32:2999-3054.

34. Montalescot G, Sechtem U, Achenbach S, et al. 2013 ESC guidelines on the management of stable coronary artery disease: the Task Force on the management of stable coronary artery disease of the European Society of Cardiology. Eur Heart J 2013;34:2949-3003.

35. Lindholm D, Varenhorst C, Cannon $\mathrm{CP}$, et al. Ticagrelor vs. clopidogrel in patients with non-ST-elevation acute coronary syndrome with or without revascularization: results from the PLATO trial. Eur Heart J 2014 April 11 (Epub ahead of print).

36. Steg PG, Harrington RA, Emanuelsson $\mathrm{H}$, et al. Stent thrombosis with ticagrelor versus clopidogrel in patients with acute coronary syndromes: an analysis from the prospective, randomized PLATO trial. Circulation 2013;128:1055-65.

37. Mehran R, Lansky AJ, Witzenbichler $\mathrm{B}$, et al. Bivalirudin in patients undergoing primary angioplasty for acute myocardial infarction (HORIZONS-AMI): 1-year results of a randomised controlled trial. Lancet 2009;374:1149-59.

38. Steg PG, van 't Hof A, Hamm CW, et al. Bivalirudin started during emergency transport for primary PCI. N Engl J Med 2013;369:2207-17.

39. Shahzad A, Kemp I, Mars C, et al. Unfractionated heparin versus bivalirudin in primary percutaneous coronary intervention (HEAT-PPCI): an open-label, single centre, randomised controlled trial. Lancet 2014 July 4 (Epub ahead of print). 40. Cohen MV, Downey JM. Combined cardioprotectant and antithrombotic actions of platelet P2Y12 receptor antagonists in acute coronary syndrome: just what the doctor ordered. J Cardiovasc Pharmacol Ther 2014;19:179-90.

Copyright @ 2014 Massachusetts Medical Society. 